\title{
Is there a Rhythm Of The Rain? An analysis of weather in popular music
}

Article

Accepted Version

Brown, S., Aplin, K. L., Jenkins, K., Mander, S., Walsh, C. and Williams, P. D. (2015) Is there a Rhythm Of The Rain? An analysis of weather in popular music. Weather, 70 (7). pp. 198204. ISSN 0043-1656 doi: https://doi.org/10.1002/wea.2464 Available at https://centaur.reading.ac.uk/40739/

It is advisable to refer to the publisher's version if you intend to cite from the work. See Guidance on citing.

Published version at: http://onlinelibrary.wiley.com/doi/10.1002/wea.2464/abstract

To link to this article DOI: http://dx.doi.org/10.1002/wea.2464

Publisher: Wiley

All outputs in CentAUR are protected by Intellectual Property Rights law, including copyright law. Copyright and IPR is retained by the creators or other copyright holders. Terms and conditions for use of this material are defined in the End User Agreement.

\section{www.reading.ac.uk/centaur}

\section{CentAUR}

Central Archive at the University of Reading

Reading's research outputs online 


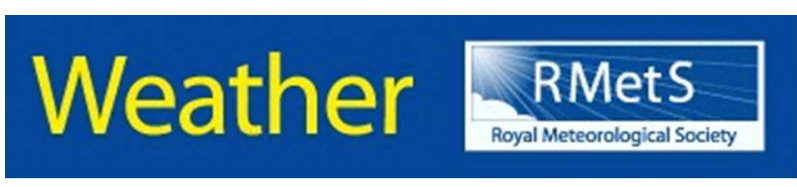

\section{Is there a rhythm of the rain? An analysis of weather in popular music}

\begin{tabular}{|r|l|}
\hline Journal: & Weather \\
\hline Manuscript ID: & WEA-14-0066.R1 \\
\hline Wiley - Manuscript type: & Research Article \\
\hline Complete List of Authors: & $\begin{array}{r}\text { Brown, Sally; University of Southampton and Tyndall Centre for Climate } \\
\text { Change Research, Faculty of Engineering and the Environment } \\
\text { Aplin, Karen; University of Oxford, Department of Physics } \\
\text { Jenkins, Katie; University of Oxford and Tyndall Centre for Climate Change } \\
\text { Research, Environmental Change Institute, Oxford Centre for the } \\
\text { Environment } \\
\text { Mander, Sarah; University of Manchester, Tyndall Centre for Climate } \\
\text { Change Research and Mechanical, Aerospace and Civil Engineering } \\
\text { Walsh, Claire; University of Newcastle and Tyndall Centre for Climate } \\
\text { Change Research, Centre for Earth Systems Engineering Research, School } \\
\text { of Civil Engineering and Geosciences } \\
\text { Williams, Paul; University of Reading, Department of Meteorology and } \\
\text { National Centre for Atmospheric Science }\end{array}$ \\
\hline Keywords: & \begin{tabular}{l} 
music, Iyrics, song, keys, weather, sun, rain \\
\hline
\end{tabular} \\
\hline
\end{tabular}

\section{SCHOLARONE \\ Manuscripts}




\title{
Is there a rhythm of the rain?
}

\section{An analysis of weather in popular music}

\begin{abstract}
Weather is frequently used in music to frame events and emotions, yet quantitative analyses are rare. From a collated base set of 759 weather-related songs, 419 were analysed based on listings from a karaoke database. This article analyses the 20 weather types described, frequency of occurrence, genre, keys, mimicry, lyrics and songwriters. Vocals were the principal means of communicating weather: sunshine was the most common, followed by rain, with weather depictions linked to the emotions of the song. Bob Dylan, John Lennon and Paul McCartney wrote the most weather-related songs, partly following their experiences at the time of writing.
\end{abstract}

\section{Key words}

Music, songs, lyrics, keys, weather, sun, rain

\section{Running head}

Weather and popular music 
Sally Brown

Faculty of Engineering and the Environment and Tyndall Centre for Climate Change Research, University of Southampton, University Road, Highfield, Southampton. SO17 1BJ. UK sb20@soton.ac.uk +44 2380594796

Karen L. Aplin

Department of Physics, University of Oxford, Denys Wilkinson Building, Keble Road, Oxford OX1 3RH, UK karen.aplin@physics.ox.ac.uk +44 1865273491

Katie Jenkins

Environmental Change Institute, Oxford Centre for the Environment, University of Oxford and Tyndall Centre for Climate Change Research, South Parks Road, Oxford, OX1 3QY, UK katie.jenkins@ouce.ox.ac.uk +44 1865275261

Sarah Mander

Tyndall Centre for Climate Change Research and Mechanical, Aerospace and Civil Engineering, The University of Manchester, Oxford Road, Manchester, M13 9QL, UK s.mander@manchester.ac.uk +44 1613063259.

Claire Walsh

Centre for Earth Systems Engineering Research, School of Civil Engineering and Geosciences, Newcastle University and Tyndall Centre for Climate Change Research, Claremont Road, Newcastle upon Tyne, NE1 7RU, UK. Claire.Walsh@ncl.ac.uk. +44 191 2226447.

Paul D. Williams 
1

2

3

4

5

6

7

8

9

10

11

12

13

14

15

16

17

18

19

20

21

22

23

24

25

26

27

28

29

30

31

32

33

34

35

36

37

38

39

40

41

42

43

44

45

46

47

48

49

50

51

52

53

54

55

56

57

58

59

60

Department of Meteorology and National Centre for Atmospheric Science, University of

Reading, Earley Gate, Reading RG6 6BB, UK. p.d.williams@reading.ac.uk +44 118378

8424

http://mc.manuscriptcentral.com/weather 


\section{Introduction}

The influence of the environment on composers, painters, writers, and other creative artists can be substantial. Several authors have analysed how our environment has influenced music: Wagner (1972) looked at weather in classical music, followed by Gedzelman (1980) and Schmid (1989), who also considered meteorology in popular music. Aplin and Williams $(2011,2012)$ recently analysed weather and classical music. Weather phenomena have also been examined with respect to certain artists and society (e.g., Robock, 2005; Kotarba et al., 2013). Furthermore, it is straightforward to find evidence that popular singers are inspired by meteorology. For example, a video of the song "Sunshine On My Shoulders"1 features singer John Denver discussing how he was inspired by nature. Also, members of the UK band Blur have explained how the Shipping Forecast (a British radio bulletin reporting on maritime weather conditions) provided inspiration for the lyrics of a half-written song, "This Is A Low" (Cavanagh and Maconie, 1995; James, 2007). Additionally, some versions of "Wind Power"2 by electronic music pioneer Thomas Dolby, also feature visual and aural representations of meteorological phenomena including pressure charts, wind vanes and the shipping forecast.

These examples indicate that discussing weather - often seen as a British obsession - is a popular pastime and much can be learnt from how society portrays weather in music, and the types of weather that inspire musicians. For example, Smiley and Post (2014) use popular music, including songs with environmental themes, as a didactic tool. They found that many students improved their critical analysis skills, when geographical and environmental concepts were linked to music. Simply put, the majority of the population have heard or can relate to a piece of weather-related music. Thus the aim of this paper is to answer the following questions:

\footnotetext{
$\overline{1} \mathrm{http}: / /$ www.youtube.com/watch?v=Hrl_VXLUcFk

${ }^{2}$ https://www.youtube.com/watch?v=SN̄yWRyMIdlY
} 
i) How well is weather represented in popular music, and what phenomena are the most commonly described?

ii) What are the common methods of communicating weather phenomena in popular and music?

iii) Are musicians influenced by weather?

We focus on karaoke songs because of the wide range of artists covered, and that the songs are well known for their lyrics, which is the principal method to communicate weather phenomena. The karaoke database was used as a starting point for analysis, so the complete versions of each song were considered, such as through artists websites, or YouTube (our choice of database is discussed further in sections Methodology and Case Studies). We apply the methodology of Aplin and Williams (2011) to compile and analyse a database of weather references in popular music. Lyrics, musical genre, musical keys, mimicry, geographical origin and links to specific weather events are all considered. In this paper, references to songs are given to both songwriters and performers. The latter is distinguished from the former by the words 'perf:' immediately preceding their name or group.

\section{Methodology}

Thousands of popular songs have been written, with many hundreds containing references to weather. Using a series of lists, databases ${ }^{3}$ and our own inspiration, 759 weather songs were found, all of which are listed in the supplementary material. To ensure a fair, consistent methodology and accurate analysis, a subset of 419 popular music songs were analysed in detail. These songs were available in a karaoke database. The most suitable was KaraFun ${ }^{4}$

\footnotetext{
${ }^{3}$ For example: karafun.com, songfacts.com, bobdylan.com, www.beatlesagain.com

${ }^{4}$ http://www.karafun.com
} 
due to size ${ }^{5}$, consistency and availability of lyrics compared with alternatives. Other sources were considered, such as Song Facts (2014), but these lists were not necessarily compiled consistently and did not state, for example, if songs were excluded if weather was mentioned in the title but not the lyrics. Although KaraFun proved to be one of the most effective databases with which to search for songs, it did have weaknesses. First, songs less appropriate for karaoke were not included (340 songs were excluded from detailed analysis from our base list as they were not in the KaraFun database. Nearly half were related to Bob Dylan. Subsequently this is addressed separately in the Case Studies section). Second, a limited number of singers were associated with each song, which can affect some songs that are repeatedly "covered" by different artists. We believe the database is representative of the wider repertoire, as discussed in the section on Lennon and McCartney.

We searched for the following meteorological references in the lyrics of the KaraFun database: Blizzard, cloud, cold (including freezing, cool), fair/blue skies, fog, frost, haze, heat/warmth, hurricane, ice, mist, rain, rainbow, seasons (including each type), snow, storm, Sun, thunder (and lightning), tornado and wind (or breeze). To ensure inclusion, selected weather impact terms were also searched as in some songs. Additionally weather phenomena are strongly implied without the use of meteorological terms. An example is the phrase 'tree tops glisten' from White Christmas (Berlin) to indicate cold, frosty or snowy conditions. In these cases reliability was ensured through iteration between the authors until agreement was reached on the appropriate weather phenomenon. We record the weather type represented, the song title, songwriter, singers/bands, year and year made famous from the karaoke database, and where possible nationality of songwriters and copyright year. Lyrics and musical characteristics of the song are also analysed. We found 419 songs (from a possible 759 based on multiple sources), referring to weather were in the KaraFun database. These are divided into two mutually exclusive categories: primary (190 songs), where weather was a theme, repeated line or chorus, and secondary (229 songs), where

\footnotetext{
${ }^{5} 15,000$ songs were available on KaraFun up to 31 December 2012
} 
weather was mentioned only in a few lines. To avoid ambiguity, the classifications were iterated between the authors, until all were satisfied with the classification. Primary songs will be analysed, with some reference to the secondary songs and where appropriate, the 340 not in KaraFun (listed in the supplementary material). Throughout our study, we assumed, following common perception in north-west Europe, that phenomena such as sun and warm temperatures are positive aspects of the weather, whilst cold, rain, thunder and rain are negative. Of course, there are exceptions to this (such as meteorologists enjoying thundery conditions, or rain being good for crops particularly in times of drought), as described in greater detail in the Lyrics section.

\section{Results}

\section{Overview}

Out of the 190 songs with weather as a primary theme, Sun and sunshine are the most common references (86 instances), followed by rain (74 references). Sun and rain represent $37 \%$ of the references to weather for both primary and secondary songs, as shown in Figure 1a. The seasons and wind/breeze are the next two most popular references in both primary and secondary songs. The frequency of weather references then varies between primary and secondary songs. Blizzards and frost are the least frequently referenced, suggesting that generic weather terms are more popular.

Many songs reference two or more weather types, as shown in Figure 1b. Secondary songs are more likely to refer to only one or two weather types per song (53\% and $30 \%$, respectively) compared to songs containing primary weather references ( $36 \%$ and $24 \%$, respectively). In contrast, songs with primary weather themes are more likely to refer to three or more weather types. The maximum number of weather types per song was six, found in 
"Baby It's Cold Outside" (Loesser), "Stormy" (Cobb and Buie) and "The Wreck Of The Edmund Fitzgerald" (Lightfoot).

[insert Figure 1 in here]

The most common combination of weather types referred to in the same song are Sun and rain. Table 1 highlights that for primary songs, 41 entries in the database refer to both Sun and rain together in the lyrics. Other common couplings include Sun and clouds; Sun and seasons; rain and clouds; and rain and storms. This is followed by seasons and cold; Sun and wind/breeze and Sun and storms. Of the songs that refer to both Sun and rain, the next most common weather type to be additionally referenced is clouds, occurring in 12 of the primary songs.

[insert Table 1 in here]

In the primary database, the number of songs containing two or more weather types is similar to the number of songs containing one weather type. In contrast, the number of songs in the KaraFun database containing any weather at all is tiny (just a few hundred out of over 15,000). Therefore, the probability of a song containing at least two weather types, given that it contains at least one weather type, is much greater than the probability of a randomly chosen song containing any number of weather types. This means that mentions of weather in pop songs tend to be clustered, which could indicate, for example, contrasting emotions in a song represented by the weather (see Lyrics section).

\section{Lyrics}

We found that lyrics, as opposed to instrumentation or other sounds, are the main mode of reference to weather-related phenomena in pop music, which made searching a karaoke database advantageous. Some secondary songs in our database have little to do with the 
weather, due to the dual meanings of meteorological words. For example "Ice Ice Baby", "Daddy Cool", "Hot Stuff" and "Bennie and the Jets", the latter for instance, being a fiction band, rather than describing fast moving wind.

Out of the 500 greatest songs of all time, listed by Rolling Stone (2011), 7\% are weather related. Over all, The Beach Boys' "Good Vibrations" is listed as the greatest weather-related songs, where the 'vibrations' 'harnessed that energy and turned it into eternal sunshine' (Wilson, quoted in Rolling Stone, 2011). However, as a secondary song, this is not commonly considered to be as a weather-related song. Twelve primary songs are found in the Rolling Stone (2011) greatest songs list, including “Blowin' In The Wind” (Dylan), "Sunshine Of Your Love" (Clapton et al.), "Purple Rain" (Prince) and "Who'll Stop The Rain" (Fogerty). Lyrics referring to weather in the context of love and relationships formed around one third of the total of primary songs. The variety of emotions associated with relationships leads to a range of positive (e.g Sun, heat) and negative (e.g., rain, storm) weather references. This is most directly shown in "When You're Smiling (The Whole World Smiles With You)" (Goodwin et al.) 'When you're laughin', when you're laughin', the sun comes shinin' through / But when you're cryin' you bring on the rain'. There are some exceptions, such as "The End Of The World" (Dee and Kent) where the Sun is perceived negatively, 'Why does the sun go on shining?'. Rainbows are often seen as positive, or appearing at times of emotional change. Weather can be used to frame an entire story, such as "Seasons in the Sun" (Brel) and "Bus Stop" (Gouldman). "Bus Stop" tells of two people brought together in the rain under an umbrella. The return of the Sun is seen negatively because the umbrella is no longer needed. Rain is also used to portray the entire emotional spectrum from positive (e.g., "Rain Is A Good Thing" (Davidson and Bryan) 'Rain makes corn'), to change (e.g., "I Love A Rainy Night" (Malloy et al.) 'Showers wash all my cares away'), or simply happiness (e.g., "Singin' In The Rain" (Brown and Freed)). Other lyrics are more cryptic, such as "MacArthur Park" (Harris) which compares a cake left out in the rain and its recipe with a broken romance. 
Our analyses showed that seasonal songs are frequently written by, or aimed at, those living in the Northern Hemisphere, where Christmas is in winter. The only exception found is "Summer" (Songwriter not listed) which describes Christmas in an Australian summer. Thirteen of the primary songs are about a winter Christmas, with only one having a religious base. Perhaps surprisingly, in Christmas songs in our primary list the word 'cold' is used less than imagined, but instead is implied through idealistic Christmas images of snow. Despite bitter weather, Christmas songs are often cheery, and refer to heat (e.g., fireplace) almost as often as snow. This may be because our happy or idealistic memories of Christmas involve spending time indoors, for example, around a warm fire, rather than being outside.

\section{Music}

This section discusses musical aspects of the meteorological references in popular songs through genre, keys, mimicry, and onomatopoeia.

\section{Genre}

We assign a musical genre to each primary song and related it to a weather type. Although many songs fit into multiple categories, for simplicity only the principal genre is used. Multiple weather types within a song are counted multiple times. Results are shown in Figure 2.

[insert Figure 2 in here]

Each music genre has between one (reggae) to 77 (rock) songs associated with it. Different weather types are reasonably well spread across musical genres, indicating that the origin or type of music does not particularly affect representation of meteorological phenomena. That said, sunshine seems to be disproportionately well-represented in jazz songs, and rainbows 
are more popular in the pre-1955 music and in soundtrack categories. Reasons for this are unclear. In classical music however, Aplin and Williams (2011) identified a clear link between the 'home climate' of a composer and the weather types they chose to depict. (It is tempting to relate the popularity of heat in reggae music to its origins in the Caribbean, but the sample size is too small to draw a conclusion). One possible explanation for this difference between popular and classical music may be the time taken to write a popular song compared to a classical work. Although there are exceptions, orchestral works tend to be longer and more complex than popular music songs, and thus take months or even years to compose, thus focusing more on climate than weather. There is evidence that some popular music composers were inspired by a few very sunny days (e.g., "Good Day Sunshine" (Lennon and McCartney), see Case Studies section). Hence an analogy can be drawn between at least some popular songs being affected by weather, whereas classical works might be more likely to reflect climate timescales. This suggestion is difficult to analyse quantitatively without knowing how long meteorologically-inspired pop songs took to write (which is hard to find), as some songwriters may take longer to write some songs and thus be inspired more by climate than weather. Even so, some artists just write about weather from their local climate, which was more common in secondary songs where weather was mentioned in passing comment, rather than a central theme. Additionally, the classical music considered by Aplin and Williams (2011) spanned the 18th century to the present day, whereas our study relies on 20th century popular music, mainly post-1955. The availability of rapid transport and electronic communication has made meteorological influences on pop writers and singers far broader than just the view out of the window, contributing to the representation of many different types of weather across many different genres of popular song.

\section{Musical keys}

Aplin and Williams (2011) found that almost all the pieces in their classical music database depicting frontal storms were in minor keys, and that all the pieces depicting fair weather 
were in major keys. Generally speaking, songs in a minor key tend to sound cold and sad (e.g., "Windmills Of Your Mind" (Bergman and Bergman)), while those in a major key tend to sound warm and happy (e.g., "You Are The Sunshine Of My Life" (Wonder)). Popular music songs were classified by keys. We distinguish only between the major and minor modes, because pop songs are often transposed into different keys within the same mode, perhaps to suit the vocal range of a particular singer. (For example, $\mathrm{C}$ major and $\mathrm{F}$ major are different keys in the same mode). If the mode shifts during a song, such as from a major key for the chorus into the relative minor key for the verses, the song was categorized as being in a 'mixed key'.

Out of the 190 primary weather songs, $168(88 \%)$ are in a major key and $22(12 \%)$ are in minor or mixed keys. The minor and mixed keys are grouped together for this analysis, because if a song is in a mixed key there is at least some aspect of sadness about it. It is interesting to compare the major fraction from this study with the findings of Schellenberg and von Scheve (2012), who examined the keys of over 1,000 popular songs from the American top 40 charts over the last five decades. In the 1960 s, $85 \%$ of the songs were in a major key, compared with only about $40 \%$ now. Therefore, compared to songs in general, weather-related songs appear to be more likely to be in a major key. Table 2 breaks down six of the weather types by key.

[insert Table 2 in here]

Some interesting findings emerge. First, if a song does not mention the Sun, there is an $86 \%$ chance it is in a major key (89/104 songs). However, if a song does mention the Sun, this increases to $92 \%$ (79/86 songs). This difference is significant at the $90 \%$ level according to the exact binomial test. Therefore, consistent with naive expectations, mentioning the Sun significantly increases the probability of being in a major key. Second, if a song is in a minor (or mixed) key, there is a $32 \%$ chance it mentions the Sun ( $7 / 22$ songs) but a $41 \%$ chance it 
mentions the rain (9/22 songs). Therefore, songs in minor (or mixed) keys appear to be more likely to mention rain than Sun, although the number of songs involved is too small to be able to attach statistical significance to this result. Third, if a song mentions the Sun, there is only an $8 \%$ chance it is in a minor (or mixed) key (7/86 songs). However, this increases to $11 \%(3 / 27$ songs) if it mentions the cold; to $12 \%$ (9/74 songs) if it mentions the rain; to $17 \%$ ( $2 / 12$ songs) if it mentions thunder; and to $22 \%$ (2/9 songs) if it mentions ice. Therefore, what is widely regarded as worse weather increases the probability of being in a minor/mixed key, although again the number of songs involved is too small to claim statistical significance. Finally, if a song in our database mentions a rainbow, there is a $100 \%$ chance it is in a major key (12/12 songs), indicating that a rainbow is often associated with the brighter side of life or a pleasant change.

As noted earlier, some mentions of the Sun in lyrics are negative or due to the absence of the Sun, e.g., "When The Sun Goes Down" (Turner) and "Ain't No Sunshine" (Withers). Therefore, the songs that appear in the Sun category of our analysis are not necessarily all happy songs, they could be sad songs about how the Sun has disappeared. Therefore, some mentions of the Sun are expected (and found) to be in minor keys. One example is "Summer in the City" (Boone et al.) which features a minor descending scale in the bass line, perhaps to create a slightly oppressive and uncomfortable feeling, which contrasts with the major key sections. Another example (listed in the supplementary material) is the song Rainbow (perf: Marmalade) whose lyrics include 'Rainbow, you were fun to have around' and 'Come on home, keep me warm'. This song is in a minor key, which is consistent with it being about the absence of a rainbow.

\section{Mimicry and onomatopoeia}

The use of mimicry - the action of imitating a noise - was found to be established in classical music, occurring in 10 out of 64 pieces (16\%) (Aplin and Williams 2011). In popular music it is less common, with only 12 out of 190 primary songs $(6 \%)$ using the technique. For 
example, the sound of plucked (pizzicato) string instruments to represent the sound and rhythm of falling rain (a popular technique amongst classical composers), is used in three pop songs: "Rain On Your Parade" (perf: Duffy), "It Might As Well Rain Until September" (perf: Carole King), and "A Year Without Rain” (perf: Selena Gomez). "Rhythm Of The Rain” (perf: The Cascades) incorporates mimicry of three weather types, by including a repetitive descending glockenspiel, with other percussion instruments imitating thunder and rain at the end of the song. This is one of the largest numbers of weather types to be copied in any one song (see Figure 1b).

As might be expected from more contemporary music, 20th century technology is used to include direct sound effects. For example, "Rain" (perf: SWV) includes a 'drip' sound in the percussion throughout, and sounds of heavy rain at the end to reinforce the lyrics about rain. "Riders on the Storm" (perf: The Doors) use thunder and rain sounds throughout. "Stormy Weather" (perf: Lena Horne) uses both "thunderclap" sounds, and several of the techniques employed in classical music (Aplin and Williams, 2011) to mimic thunder and rain. Different covers have different interpretations: Tina Turner's version of "I Can't Stand The Rain" (Peebles et al.) features rain and thunder noises throughout, whereas Seal's performance only has the sound effects at the start, opting for rhythmic repetitions of the word 'rain' towards the end, almost representing the sound itself. Wind is often copied using a variety of techniques, several of which are included in the country music song "North Wind" (perf: Slim Whitman). Portamento sounds, sliding from one note to another, are used in the guitar. The song also features a wind machine, and the vocalist using chromatic phrase endings to echo the sliding effects in the guitar. The voice can of course be used to directly copy the howling or whooshing sounds of wind, particularly with portamenti (e.g., "Wild Is The Wind" (perf: David Bowie)) or in non-verbal choruses using an 'ooh' or 'aah' sound (“Windy" (perf: The Association)). This song also builds up a chord from the bottom using the voices of the singers to rise 'above the clouds' in the lyrics. 
Some meteorological sound effects do not use direct mimicry, but are still effective at summoning a particular mood. For example, the use of bells is associated with winter and Christmas by many people, as noted in "White Christmas", and "I Wish It Could Be Christmas Every Day". The opposite effect is achieved in "Here Comes The Sun" (perf: The Beatles) by the use of a Hawaiian guitar, which can be mentally linked to the warmer Hawaiian climate (relative to a British summer). "Mr Blue Sky" (perf: Electric Light Orchestra) uses a snippet of an optimistic weather forecast to set up the happy mood of the song.

\begin{abstract}
As well as simple mimicry with non-verbal sounds, lyrics of pop songs can include onomatopoeia, in which the sound of a word mimics what the word describes. Interestingly, words describing weather can be pronounced in an unexpected way, for example thunder or wind may be quite soft (e.g., "Storms Never Last", "Wild Is The Wind"). Wind is probably the most recognisable form of onomatopoeia, as the word 'wind' can stretch and slide, as in the portamento in "North Wind". In "The Thunder Rolls", the singer uses a range of ornamentation techniques, such as mordents and trills, on the word 'rolls' to give a 'rumbling' effect. Although not strictly onomatopoeic, the song "Oh What A Beautiful Mornin"” uses a rising chromatic scale to represent 'climbing clear up to the sky'.
\end{abstract}

\title{
Connectivity, and inspiration from weather events
}

Weather inspired songs are reflected in our primary songs either through a central weatherrelated storyline (e.g., "Who'll Stop The Rain" (Fogerty)), or as an analogy, metaphor or metonymy (e.g., "Get Off Of My Cloud" (Richards)). A distinct example is from Canadian Gordon Lightfoot, who in 1976, wrote and composed the song "The Wreak Of The Edmund Fitzgerald" in tribute to the eponymous freight ship that sank with the loss of $29 \mathrm{crew}$ the previous year. However, finding evidence in other songwriters who were directly influenced by a weather event, rather than writing more generally about the weather is challenging. For 
songs with a central weather-related storyline, inspiration could come from a particularly sunny day or a series of events (weather related or otherwise). To determine this, the copyright years of songs (where available; only 91 out of 190 were found for primary songs) are compared against actual weather events. Of the 33 songs in the subset from the 1950 s and 1960 s, $73 \%$ (24 songs) mention storms, wind, rain, or hurricanes. In contrast, of the 26 songs in the subset from the 1970 s and 1980s, when there were fewer hurricanes, only $46 \%$ (12 songs) mention these keywords. In the USA during the 1950s and 1960s, there was much severe weather, including hurricanes Betsy, Hazel, Carol, Donna, and Carla (Changnon and Changnon, 1992). Under the null hypothesis that 1950 s and 1960s songs have the same probability of mentioning these keywords as 1970 s and 1980 s songs, the number of 1950 s and 1960 s songs to mention these keywords is distributed according to the binomial distribution $\mathrm{B}(N, p)$ with $N=33$ and $p=0.46$. According to this distribution, the probability of obtaining at least 24 songs is only $0.2 \%$. Therefore, we can reject the null hypothesis at the $99.8 \%$ level. We conclude that references to bad weather in pop songs were significantly more likely in the stormy 1950 s and 1960s than in the relatively quiet 1970s and 1980s when considering conditions in the USA. Conversely, in the UK, the 'neverending summer' (above average sunshine and temperatures) of 1959 was subsequently followed by poor summers (cool conditions, and at times wet) in the 1960s and early 1970s (Meteorological Office, 1959; 1962; 1971). Despite this, $54 \%$ of 1960 s songs mentioning the Sun were by British songwriters, e.g., "I'll Follow The Sun" (Lennon and McCartney).

Meteorological lyrics occasionally also mention specific days of the week, particularly Sunday, e.g., the American-written "Sunday Morning" (Carmichael et al.) 'Sunday morning rain is falling', and "Raining On Sunday" (Brown and Foster) 'When it's raining on Sunday'. Whilst this may represent feelings associated with a traditionally quieter or less interesting day of the week, the references to weekend rainfall may not be entirely fanciful, as weekly cycles of air pollutants have been claimed to be linked to more precipitation in the north- 
west Atlantic region of the USA at weekends (Cerveny and Balling, 1998). Weekly cycles have also been identified in German weather patterns due to interactions between aerosols and atmospheric dynamics (Bäumer and Vogel, 2007). No unambiguous conclusions can be drawn linking specific or cyclonic weather events to meteorological references in pop songs.

\section{Case studies}

Our study found over 900 different songwriters and singers portraying weather in 418 songs. Concentrating on lyricists, Lennon and McCartney have the most number of songs in our primary database (e.g., "I'll Follow The Sun", "Rain”, and "Good Day Sunshine”), whereas overall (including songs not found in KaraFun, as listed in the supplementary material), the most weather-related songs are by Bob Dylan. (e.g., "Blowin' In The Wind", “Just Like A Woman"). We note that Lennon and McCartney would of course stand out in the database, not only because they were prolific songwriters but also because many of their songs are ideal for inclusion in a karaoke songlist. Other musicians have many weather songs in one album, such as XTC's “Skylarking”.

\section{Bob Dylan}

Bob Dylan's songs are well known to mention weather phenomena (Robock, 2005). Out of 542 songs sung, and mainly written by him, 163 were found to contain weather references (see supplementary material), in particular to wind and Sun. Six of his weather-related songs are in Rolling Stone's (2011) greatest songs of all time - the most out of any artist. As with other artists, Dylan's songs often clustered different weather types. This paper has not attempted a detailed study of Dylan since these already exist (Robock, 2005; Epstein, 2011). 
Although Dylan produced his 33rd album under the meteorological pseudonym Jack Frost (Epstein, 2011), there is little direct evidence of him being specifically influenced by the weather. Instead, atmospheric phenomena, as experienced by everyone, are simply used as a powerful allegorical tool. However, one instance of Dylan being directly affected by a meteorological event is that he resurrected and edited the 1920s blues song "When the Levee Breaks" in 2005 after the flooding in New Orleans. Interestingly, Dylan also presented a weather-themed radio programme (Theme Time Radio Hour) on 3rd May 2006 (Epstein, 2011), on which meteorologically influenced songs were played. Although the programme had a different theme every time, the choice of weather over other possible themes is again circumstantial evidence for the weather acting as a rich creative inspiration. As Dylan himself said on the show, 'Curious about what the weather looks like? Just look out your window and take a walk outside' (Epstein, 2011). It is possible that Dylan's upbringing in the severe continental climate experienced by the state of Minnesota could have instilled a deep appreciation for the weather within him.

\section{John Lennon and Paul McCartney}

"Rain" was provoked by a trip to Melbourne, Australia, about which Lennon stated, 'I've never seen rain as hard as that, except in Tahiti' (McCartney et al., 2000). Lennon later explained that the song was about 'people moaning about the weather all of the time' although some analyses believe the lyrics also reflected Lennon's state of mind at the time (Turner, 1999). The lyrics are strongly metaphorical, suggesting that people hiding from the rain 'may as well be dead', whilst the Sun is used to imply a more positive outlook. Part of the song involves the (then) new technique of playing a taped guitar sound backwards, to represent rain (McCartney et al., 2000).

Similarly, in "Good Day Sunshine", written by McCartney whilst in a good mood during a 'particularly sunny day' (Turner, 1999), the love story told is heightened by the weather. George Harrison wrote "Here Comes The Sun" after he left a business meeting early and 
disgruntled in April 1969. Rowley (2013) documents that April 1969 had 189 hours of sunshine (recorded by the nearby Greenwich meteorological station), a record that was not surpassed until 1984. The day the song was written was the 'first sunshine of the year' (Turner, 1999), which was perhaps appropriate or sign of relief the sunshine had finally showed its warmth after colder than average conditions seen in March of that year. George Harrison stated, 'It was such a great release for me simply being out in the sun...The song just came to me'. Furthermore, Harrison in his autobiography describing this song states 'it seems as if winter in England goes on forever, by the time spring comes you really deserve it' (Harrison, 1980). This may also be reflected in the lyrics of the song, where Harrison referred to the 'long, cold lonely winter' in the lyrics.

We will address the issue of how representative the KaraFun database is of the wider repertoire of songs. For example, for the Beatles, 48 (16\%) of their total output of 308 songs mention a weather type ${ }^{6}$, whereas $27(17 \%)$ of their 157 songs in the KaraFun database mention a weather type. Under the null hypothesis that the KaraFun database is representative, the number of Beatles' weather songs in Karafun is distributed according to the binomial distribution $\mathrm{B}(N, p)$ with $N=157$ and $p=0.16$. According to this distribution, the probability of obtaining at least 27 weather songs by chance is $32 \%$. Therefore, since there is no convincing evidence to reject the null hypothesis we conclude that from the perspective of weather references in the Beatles' songs, the KaraFun database is representative. There is less evidence of representivity for Bob Dylan's songs, possibly because the number of his songs in the KaraFun database is relatively low.

\section{Songwriters and artists}

\footnotetext{
${ }^{6}$ As searched for on www.beatlesagain.com
} 
Performing artists and bands have a wide variety of names, and these too include some with weather-related themes, such as Coldplay, Vanilla Ice, Wet Wet Wet, KC and the Sunshine Band, The Weather Girls and The Storm. Our database contained a total of 30 artists, lyricists, or band names relating to ten weather types. In common with the depictions in songs, Sun is the most popular weather type, appearing in seven band names, followed by cold (four) and heat (three).

\section{Conclusions}

Artistic inspiration is drawn from the weather, yet in music quantitative analysis has hitherto been limited. We found 759 weather-related songs and detailed analysis was undertaken of 419 by searching an online karaoke database. Of that, $45 \%$ featured weather as a primary theme, such as repeated words found in a chorus.

References to weather are often described and clustered in the lyrics, with Sun and rain being the most common. Unsurprisingly, the Sun portrayed positive feelings and is more likely to be in a major key, whereas rain could frame either good or bad emotions, so has a higher likelihood than Sun of being in a minor or mixed key. The key effect was stronger in popular songs than in classical orchestral music (Aplin and Williams, 2011). There is some evidence linking weather depicted in pop songs to contemporaneous weather conditions, such as poor weather being more common in the stormy 1950 s and 1960s than the calmer 1970s and 1980s. No significant relationship is found between musical genre and weather type. Only a few songwriters repeatedly target the weather as a specific theme for their songs, the most prolific artists being Bob Dylan and John Lennon and Paul McCartney. Over 30 artists, lyricists, or bands had names relating to the weather. 
Taken together, these suggest that there is a universal and strong effect of weather and climate in popular musical culture. Further research could include a deeper analysis of weather-related songs by genre, by particular songwriters, by learning more about what inspires songwriters to write weather related music. It might also be possible to expand the study to consider songs written in other languages. Further analysis is also required of an additional 340 songs (nearly half by Bob Dylan) which were not in the karaoke database used, but which are noted in the supplementary material. We welcome suggestions for weather-related songs not already featured in our lists.

\section{Acknowledgements}

We thank Alice Bows-Larkin, Shaun Brown, Alistair Ford, and Carly McLachlan from the Tyndall Centre for Climate Research for their contributions to our database, which was inspired by an event at Cardiff University organised by the Centre.

\section{References}

Aplin K, Williams PD. 2011. Meteorological phenomena in Western classical orchestral music. Weather, 66(11):300-306. doi:10.1002/wea.765

Aplin KL, Williams PD. 2012. Whether weather affects music, Eos. Trans. American Geophys. Union, 93(36):347. doi:10.1029/2012EO360007

Bäumer D, Vogel B. 2007: An unexpected pattern of distinct weekly periodicities in climatological variables in Germany. Geophys. Res. Lett., 34:L03819, doi:10.1029/2006GL028559 
Cavanagh D, Maconie S. 1995. How did they do that?, Select, July.

Cerveny RS, Balling Jr, JC. 1998. Weekly cycles of air pollutants, precipitation and tropical cyclones in the coastal NW Atlantic region. Nature, 394:561-563

Changnon SA, Changnon JM. 1992. Temporal fluctuations in weather disasters: 19501989. Clim Change 22:191-208.

Epstein DM. 2011. The Ballad of Bob Dylan: A Portrait. Harper: London.

Gedzelman DS, 1980. Science and Wonders of the Atmosphere. John Wiley and Sons

James A. 2007 Bit of a Blur. Abacus: London.

Harrison G. 1980. I, Me, Mine. Genesis Publications Limited: London.

Kotarba JA, Merrill B, Williams JP, Vannini P. 2013 Understanding society through popular music, 2nd edition, Routledge: New York.

McCartney P, Harrison G, Starr R, Ono Y. 2000. The Beatles Anthology. Cassell: London.

Meteorological Office 1959 Monthly weather report of the Meterological Office. 76(8) August 1959 Her Majesty's Stationery Office. http://www.metoffice.gov.uk/media/pdf/f/r/Aug1959.pdf Accessed October 2014

Meteorological Office 1962 Monthly weather report of the Meterological Office. 79(8) August 1962. Her Majesty's Stationery Office.

http://www.metoffice.gov.uk/media/pdf/1/b/Aug1962.pdf Accessed October 2014 
Meteorological Office 1971 Monthly weather report of the Meterological Office. 88(8) August 1971. Her Majesty's Stationery Office.

http://www.metoffice.gov.uk/media/pdf/m/q/Aug1971.pdf Accessed October 2014

Robock A. 2005. "Tonight as I stand inside the rain”: Bob Dylan and weather imagery, Bull. Amer. Meteor. Soc., 86(4): 483-487. doi: 10.1175/BAMS- 86-4-483.

Rolling Stone 2011. 500 greatest songs of all time.

http://www.rollingstone.com/music/lists/the-500-greatest-songs-of-all-time-20110407 Accessed May 2014

Rowley D. 2013. All Together Now, the ABC of the Beatles songs and albums. Troubador Publishing Ltd: Leicester.

Schellenberg EG, von Scheve C. 2012. Emotional cues in American popular music: Five decades of the Top 40. Psychol. Aesthet., Creativity, and the Arts, 6(3):196-203.

Schmid R. 1989. Rockin'Thunder. Weatherwise, 42(4):192-196.

Smiley SL, Post C. 2014. Using popular music to teach the geography of the United States and Canada. J. Geog. DOI:10.1080/00221341.2013.877061

Songfacts 2014. Songs with weather conditions in the title. http://www.songfacts.com/category-songs_with_weather_conditions_in_the_title.php Accessed May 2014 
Turner, S. 1999. A Hard Day's Write. Index Books Ltd.: Dubai.

Wagner AJ. 1972. Music to Watch Weather By. Weatherwise, 25(4):168-173. 
Figure 1 (a): Most popular weather types referred to the karaoke song database. In the labels 'Fair' refers to fair weather or blue sky, and 'Thunder' includes lightning. (b) Number of songs with multiple weather references. In the legend, 'primary' songs use weather as a theme, repeated line or chorus, and 'secondary' references mention weather only in passing. The number of secondary songs (light grey) is stacked on top of the primary songs (dark grey), so that each bar represents the sum of the two groups.

Figure 2: Weather types represented in each major popular music genre. Some similar types of weather have been combined to increase the sample size (e.g., hurricanes and tornadoes; fog, mist and haze). 'Thunder' also includes lightning. The bars are in the same order as the legend from the bottom upwards. 


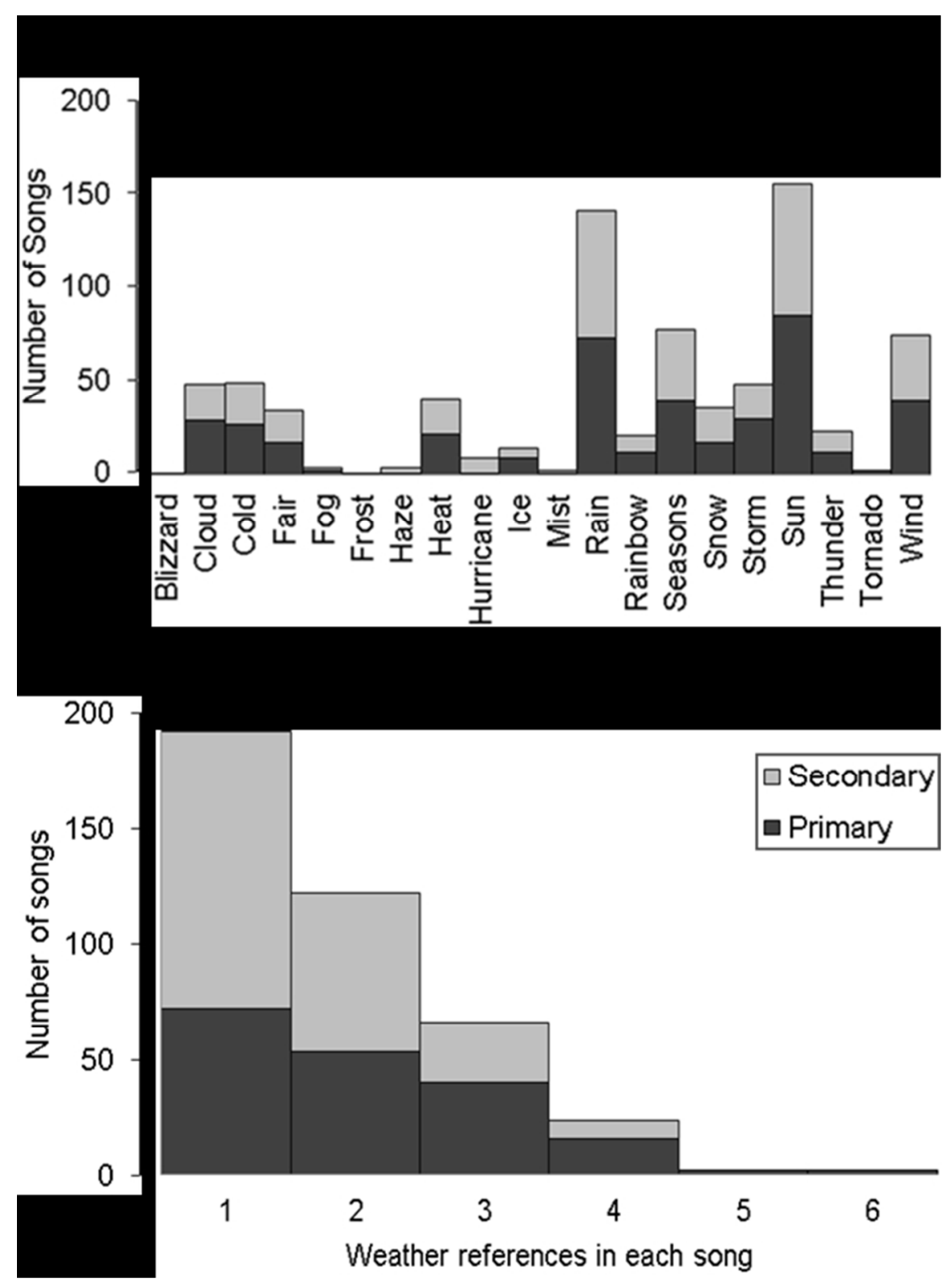

Figure 1 (a): Most popular weather types referred to the karaoke song database. In the labels 'Fair' refers to fair weather or blue sky, and 'Thunder' includes lightning. (b) Number of songs with multiple weather references. In the legend, 'primary' songs use weather as a theme, repeated line or chorus, and 'secondary' references mention weather only in passing. The number of secondary songs (light grey) is stacked on top of the primary songs (dark grey), so that each bar represents the sum of the two groups.

\section{$112 \times 153 \mathrm{~mm}(150 \times 150 \mathrm{DPI})$}




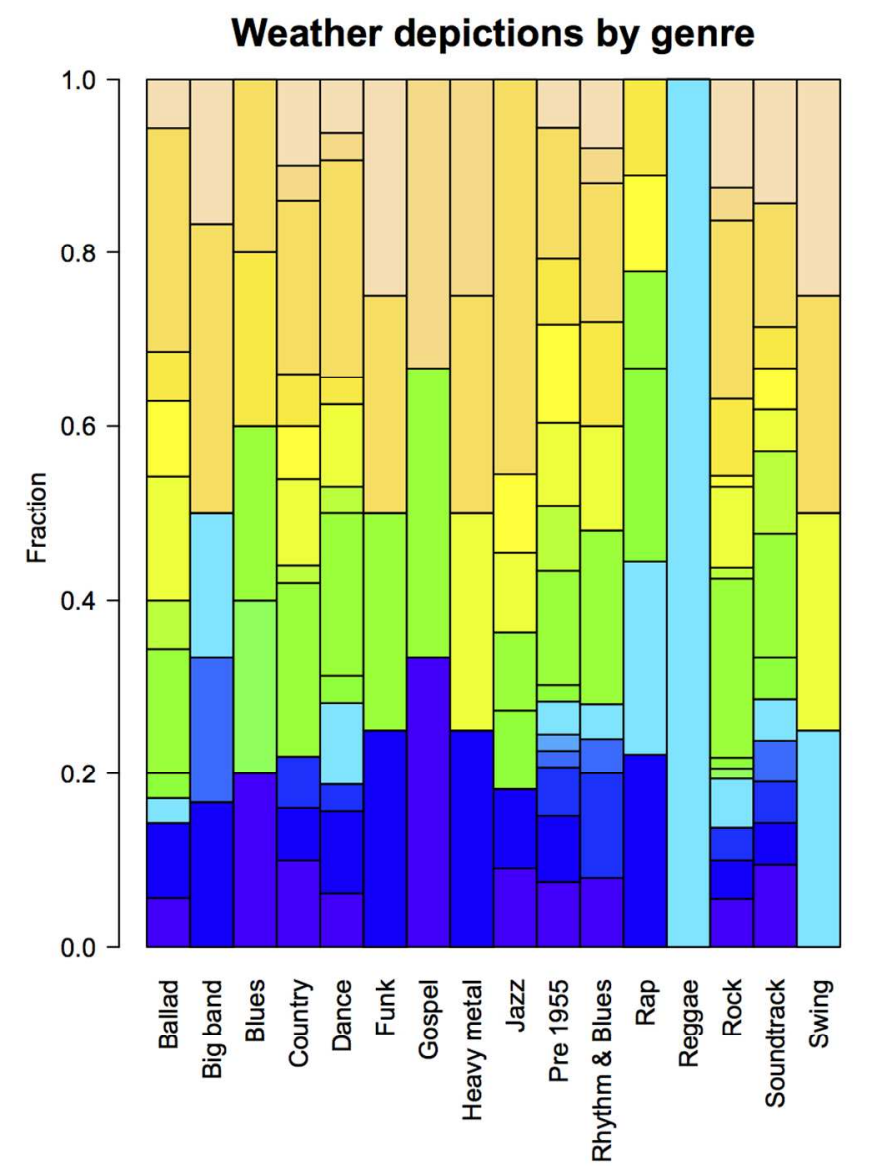

Figure 2: Weather types represented in each major popular music genre. Some similar types of weather have been combined to increase the sample size (e.g., hurricanes and tornadoes; fog, mist and haze). 'Thunder' also includes lightning. The bars are in the same order as the legend from the bottom upwards $189 \times 172 \mathrm{~mm}(200 \times 200 \mathrm{DPI})$ 
Table 1: Most common weather types which appear together in primary songs.

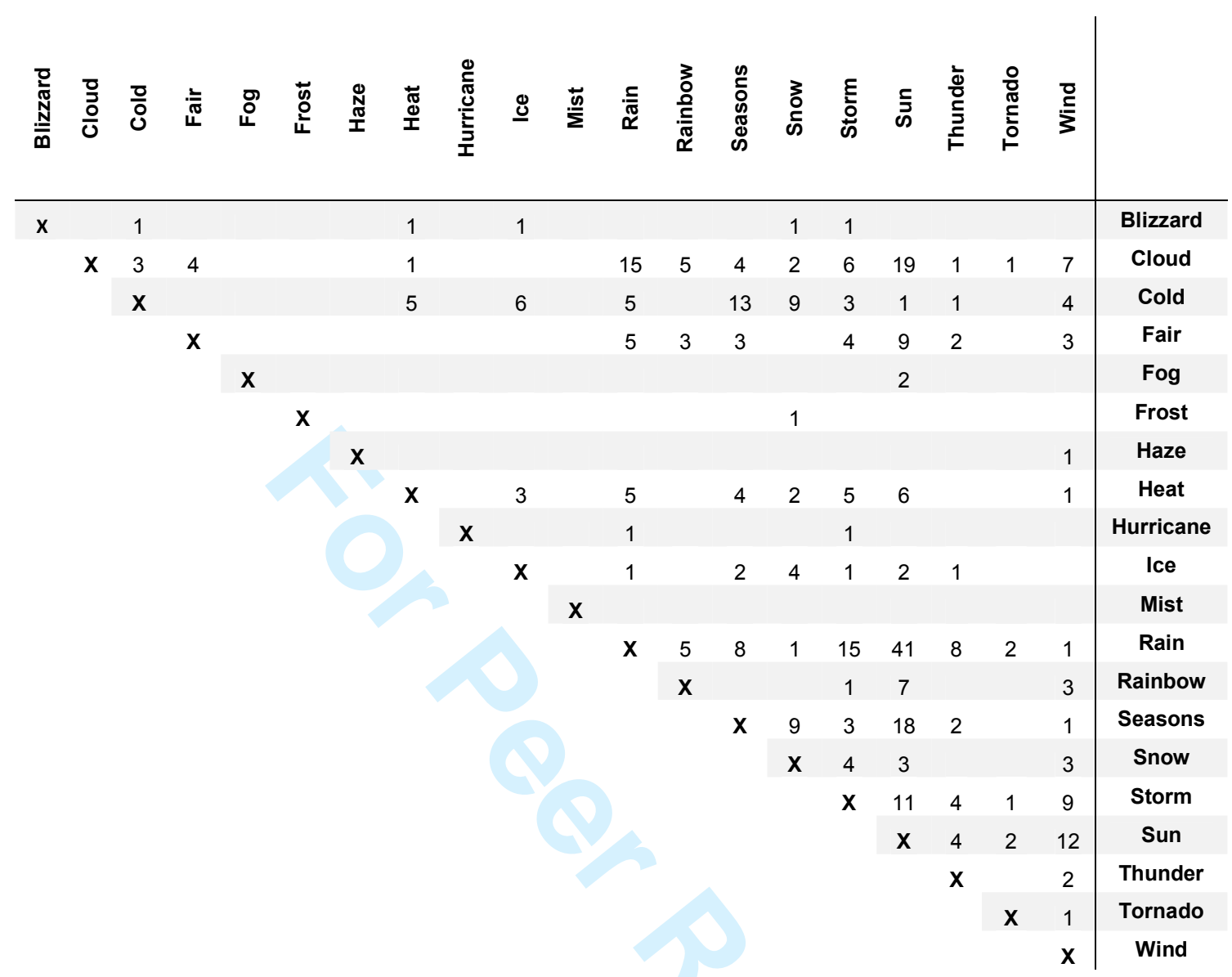


Table 2: The distribution of musical keys for the 190 primary weather songs for six weather types.

\begin{tabular}{cccc}
\hline & \# major out of 168 & \#minor/mixed out of 22 & total \\
& & & \\
\hline SUN Present & 79 & 7 & 86 \\
SUN Absent & 89 & 15 & 104 \\
RAIN Present & 65 & 9 & 74 \\
RAIN Absent & 103 & 13 & 116 \\
COLD Present & 24 & 3 & 27 \\
COLD Absent & 144 & 19 & 163 \\
THUNDER Present & 10 & 2 & 12 \\
THUNDER Absent & 158 & 20 & 178 \\
ICE Present & 7 & 2 & 9 \\
ICE Absent & 161 & 20 & 181 \\
RAINBOW Present & 12 & 0 & 12 \\
RAINBOW Absent & 156 & 22 & 178 \\
& & &
\end{tabular}

20

21

22

23

24

25

26

27

28

29

30

31

32

33

34

35

36

37

38

39

40

41

42

43

44

45

46

47

48

49

50

51

52

53

54

55

56

57

58

59

60 